\title{
Experimental Study and Extended Finite Element Simulation of Fracture of Self-Compacting Rubberized Concrete
}

\author{
Xinquan Wang $\left(\mathbb{D},{ }^{1}\right.$ Hongguo Diao $\mathbb{D}^{1},{ }^{1}$ Yunliang Cui, ${ }^{1}$ Changguang Qi, ${ }^{2}$ and Shangyu Han ${ }^{3}$ \\ ${ }^{1}$ Zhejiang University City College, Hangzhou 310015, China \\ ${ }^{2}$ College of Architecture, Civil Engineering and Environment, Ningbo University, Ningbo 315211, China \\ ${ }^{3}$ College of Civil and Architectural Engineering, Nanchang Hangkong University, Nanchang 330063, China
}

Correspondence should be addressed to Hongguo Diao; diaohg@zucc.edu.cn

Received 25 October 2020; Revised 1 January 2021; Accepted 5 April 2021; Published 20 April 2021

Academic Editor: Loke Foong

Copyright ( $\odot 2021$ Xinquan Wang et al. This is an open access article distributed under the Creative Commons Attribution License, which permits unrestricted use, distribution, and reproduction in any medium, provided the original work is properly cited.

Self-compacting rubberized concrete (SCRC) is a high-performance concrete that can achieve compacting effect by self-gravity without vibration during pouring. Because of its excellent fluidity, homogeneity, and stability, the application of self-compacting concrete in engineering can improve work efficiency and reduce project cost. The effects of loading rate on the fracture behavior of self-compacting concrete were studied in this paper. Three-point bend (TPB) tests were carried out at five loading rates of $1,0.1$, $0.001,0.0001$, and $0.00001 \mathrm{~mm} / \mathrm{s}$. The dimensions of the specimens were $100 \mathrm{~mm} \times 100 \mathrm{~mm} \times 400 \mathrm{~mm}$. A precast crack was set in the middle of the specimen with a notch-depth ratio of 0.4 . The experimental results show that the peak load on the load-CMOD (crack mouth opening displacement) curve gradually increases with the increase of the loading rate. Although the fracture energy a presented greater dispersion under the loading rate of $1 \mathrm{~mm} / \mathrm{s}$, the overall changes were still rising with the increase of the loading rate. Besides studying the softening characteristics of the self-compacting concrete, the constitutive softening curve of the self-compacting concrete was obtained using the bilinear model. Finally, curved three-point bending beams were simulated by using the extended finite element method based on ABAQUS. The fracture process of the self-compacting concrete under different loading conditions was analyzed more intuitively. The simulation results were compared with the experimental results, and the same conclusions were obtained.

\section{Introduction}

Finite element analysis rapid development of the automobile industry has led to a sharp increase in the number of discarded tires. A large number of them have caused tremendous pressure on the ecological environment [1]. Because rubber has the advantages of good toughness and fatigue resistance, mixing rubber particles into concrete can improve the toughness [2], deformation ability [3], and crack resistance [4] of concrete. This provides a compelling new way for the large-scale use of abandoned tires. Simultaneously, due to its excellent performance, self-compacting concrete (SCC) can reduce the dependence on complex manual operation in the concrete construction process, so many complex structural projects favor it.

There have been many researches on SCC at home and abroad. Massana Jordi et al. and Mostafa Jalal et al. studied the durability of high-performance SCC $[5,6]$; Persson [7] carried out a comparative study on the performance of SCC and ordinary concrete; besides, Choi et al. studied the fluidity and mechanical properties of SCC [8].

However, SCC still has some problems such as low tensile strength, high brittleness, and easy cracking [9]. To improve the crack resistance of SCC, some scholars put forward to mix rubber particles into it to enhance the performance of concrete by using the high-quality characteristics of rubber [10]. As a new kind of composite material, the research on SCRC is still in the aspects of working performance and basic mechanical properties [11-16]. The fracture characteristics of SCRC are an essential research area in the design of concrete components. However, there are little researches on the fracture characteristics of SCRC. Besides, some scholars at home and abroad have studied the effect of loading rate on the mechanical properties of 
concrete $[17,18]$, but few studies have been conducted on SCRC.

As a quasibrittle material, the fracture process of concrete is the most basic research content. Significantly, fracture propagation's fracture energy is the focus of the research [19-22]. The concrete member's fracture is a very complicated process, often accompanied by the development of significant crack, secondary crack, and microcrack. To study the fracture behavior of concrete more intuitively and accurately, many scholars have adopted the combination of experimental tests and numerical simulation to check. Numerical simulation can effectively compensate for conventional experiments' shortcomings in many aspects [23-25].

In this paper, the fracture behavior of SCRC with prefabricated cracks under different loading rates is numerically simulated. The influence of loading rate on fracture energy of concrete is studied, and a bilinear softening constitutive model is established. It is applied to ABAQUS to accurately predict the fracture behavior of rubber self-compacting concrete beams under different loading rates.

\section{Materials and Experimental Details}

\subsection{Material}

(1) P.O 42.5 ordinary Portland cement is adopted, and its relevant physical properties are shown in Table 1.

(2) The fly ash used in this test is first-grade fly ash, and the chemical components and physical properties of silica fume and fly ash are shown in Table 2.

(3) In this study, natural river sand was used as fine aggregate, and ordinary gravel was used as coarse aggregate. Due to the excessive total will having a certain degree of adverse impact on the concrete specimens, combined with the experimental materials and experimental factors' requirements, the maximum particle size of the coarse aggregate in this test is not more than $20 \mathrm{~mm}$. The physical properties and gradation of the crushed stone are shown in Table 3 .

(4) The rubber particles used in this experiment are made by cutting rubber tires at room temperature. The performance parameters of rubber particles are shown in Table 4.

(5) The admixture used in this experiment is a polycarboxylic acid-type water reducer.

2.2. Mixture Proportions. The mixture proportion of SCRC designed by our institute is shown in Table 5.

To ensure that the rubber particles can be evenly distributed in the concrete matrix, the rubber particles and other concrete components were predried and mixed for 2 minutes before the concrete was prepared by mixing with water. Fresh rubber self-compacting concrete was formed in a mold of $100 \mathrm{~mm} \times 100 \mathrm{~mm} \times 400 \mathrm{~mm}$. At the same time, $150 \mathrm{~mm} \times 150 \mathrm{~mm} \times 150 \mathrm{~mm}$ cubic specimens were poured to measure the compressive strength. All samples were disassembled after 24 hours and then soaked in a water tank for maintenance. The compressive strength test results of the cube specimens after 28 days averaged $28.76 \mathrm{MPa}$. The other basic mechanical properties of the concrete samples used in the test are shown in Table 6.

2.3. Three-Point Bending (TPB) Test. The flexural tests are carried out under TPB loading on the MTS testing machine, as shown in Figure 1. The specimens' sizes were all $100 \mathrm{~mm} \times 100 \mathrm{~mm} \times 400 \mathrm{~mm}$, and a crack with a length of $40 \mathrm{~mm}$ was prefabricated in the middle of the specimen. The span is $300 \mathrm{~mm}$, as shown in Figure 2. The crack opening displacement (CMOD) was measured using a clip-on gauge produced by MTS in us. The load is controlled by displacement. The influence of different loading rates on the fracture characteristics of SCRC was studied by using five different loading rates, namely, $1 \mathrm{~mm} / \mathrm{s}, 0.1 \mathrm{~mm} / \mathrm{s}$, $0.001 \mathrm{~mm} / \mathrm{s}, 0.0001 \mathrm{~mm} / \mathrm{s}$, and $0.00001 \mathrm{~mm} / \mathrm{s}$. Due to the contingency of the experiment, three standard specimens were selected for each loading rate.

\section{Results and Discussion}

3.1. Effect of Loading Rate on Peak Load. To study the influence of different loading rates on the peak load of concrete, the author carried out a TPB test on concrete specimens with a notch-depth ratio of 0.4 at different loading rates $(1 \mathrm{~mm} / \mathrm{s}, 0.1 \mathrm{~mm} / \mathrm{s}, 0.001 \mathrm{~mm} / \mathrm{s}, 0.0001 \mathrm{~mm} / \mathrm{s}$, and $0.00001 \mathrm{~mm} / \mathrm{s}$ ), using three specimens for each loading rate.

Figure 3 compares the peak load at different loading rates. We can intuitively find that the peak load increases with the increase of the loading rate. When the loading rate is $1 \mathrm{~mm} / \mathrm{s}$, the peak load is about $5.4 \mathrm{kN}$. When the loading rate drops to $0.00001 \mathrm{~mm} / \mathrm{s}$, the peak load is about $3.3 \mathrm{kN}$, down about $38 \%$. It can be seen that the loading rate has a significant effect on the peak load of concrete. The failure time of concrete specimens is longer when the loading rate is lower. During this period, the cracks generated by loading will extend along the interface transition zone's weakest area [26]. However, the loading period is shorter when the loading rate is higher, and the cracks will spread directly through the aggregate. The aggregate's toughness is generally higher than that of the interface transition zone, which is the main reason for the increase of peak load with the loading rate growth.

However, it is impossible to infer that the microcrack increases with the increase of loading rate by observing the specimen's cross section with the naked eye. To prove this, Figure 4 shows the fracture surfaces of concrete examples at five loading rates. Although there are five orders of magnitude differences in loading rates, the five fracture surfaces are similar.

3.2. Fracture Energy. The fracture energy $(G f)$ of the concrete specimen is an essential fracture mechanics parameter, so it is necessary to establish a precise method to determine concrete fracture energy. Under load, a TPB specimen with 
TABLE 1: The performance parameters of cement used in this experiment.

\begin{tabular}{lccccc}
\hline $\begin{array}{l}\text { Density }(\mathrm{g} / \\
\left.\mathrm{cm}^{3}\right)\end{array}$ & $\begin{array}{c}\text { Specific surface area }\left(\mathrm{m}^{2} /\right. \\
\mathrm{kg})\end{array}$ & $\begin{array}{c}\text { Fineness } \\
\text { modulus }\end{array}$ & $\mathrm{pH}$ & $\begin{array}{c}\text { Loss on ignition } \\
(\mathrm{LOI})\end{array}$ & $\begin{array}{c}\text { Standard consistency water consumption } \\
(\%)\end{array}$ \\
\hline 3.10 & 370 & 2.7 & 11.5 & 1.99 & 26.8 \\
\hline
\end{tabular}

TABLE 2: Related parameters of mineral admixtures.

\begin{tabular}{lccccccc}
\hline & $\mathrm{SiO}_{2}$ & $\mathrm{Al}_{2} \mathrm{O}_{3}$ & $\mathrm{Fe}_{2} \mathrm{O}_{3}$ & $\mathrm{CaO}$ & $\mathrm{MgO}$ & $\mathrm{SO}_{3}$ & Density $\left(\mathrm{g} / \mathrm{cm}^{3}\right)$ \\
\hline Fly ash & 55.2 & 22.17 & 6.69 & 4.24 & 2.32 & 1.09 & 2.25 \\
Silica fume & 90.5 & 0.7 & 1.5 & 0.3 & 0.6 & 1.3 & 1.78 \\
\hline
\end{tabular}

TABle 3: Physical properties and gradation of crushed stone.

\begin{tabular}{|c|c|c|c|c|}
\hline Apparent density $\left(\mathrm{kg} / \mathrm{m}^{3}\right)$ & \multicolumn{2}{|c|}{ Maximum particle size (mm) } & \multicolumn{2}{|c|}{ Crushing index (\%) } \\
\hline 2650 & \multicolumn{2}{|c|}{20} & \multicolumn{2}{|c|}{8.27} \\
\hline Grain size (mm) & $<2.36$ & $2.36-4.75$ & $4.75-9.6$ & $>9.6$ \\
\hline Proportion (\%) & 0.4 & 13.0 & 73.5 & 13.1 \\
\hline
\end{tabular}

TABLE 4: The performance parameters of rubber particles.

\begin{tabular}{lcccc}
\hline Apparent density $\left(\mathrm{kg} / \mathrm{m}^{3}\right)$ & Stacking density $\left(\mathrm{kg} / \mathrm{m}^{3}\right)$ & Carbon ash content $(\%)$ & Dust burdening $(\%)$ & Tensile strength $(\mathrm{MPa})$ \\
\hline 1060 & 433 & 18 & 2.4 & 11 \\
\hline
\end{tabular}

TABLE 5: The mixture proportion of SCRC $\left(\mathrm{kg} / \mathrm{m}^{3}\right)$.

\begin{tabular}{lccccccc}
\hline Cement & Fly ash & Silica fume & Water & Water reducer & Sand & Gravel & Rubber particles \\
\hline 385 & 139 & 26 & 200 & 7.3 & 916.2 & 800 & 41.5 \\
\hline
\end{tabular}

TABLE 6: Mechanical properties of SCRC.

\begin{tabular}{lcc}
\hline Material property & Value & Unit \\
\hline Compressive strength & 28.76 & $\mathrm{MPa}$ \\
Split tensile strength & 2.70 & $\mathrm{MPa}$ \\
Modulus of elasticity & 30.7 & $\mathrm{GPa}$ \\
\hline
\end{tabular}

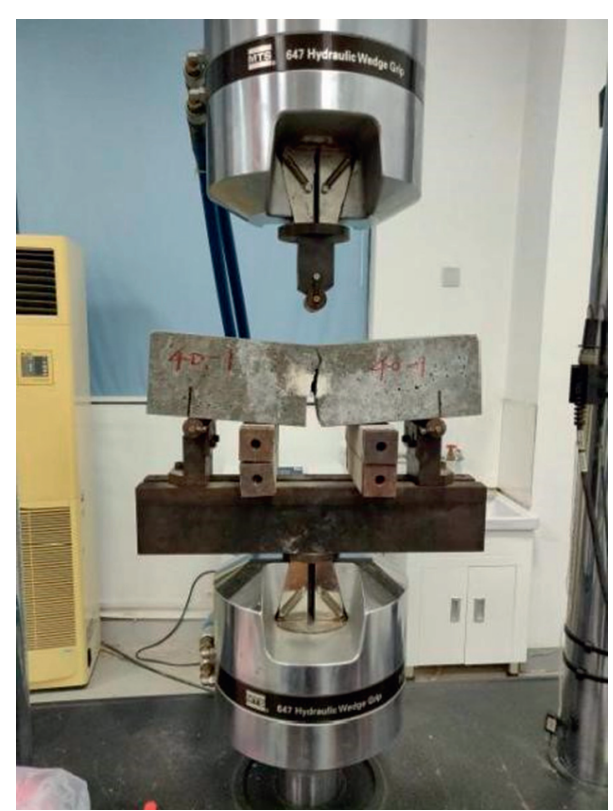

FIGURE 1: Diagram of experimental apparatus for fracture.

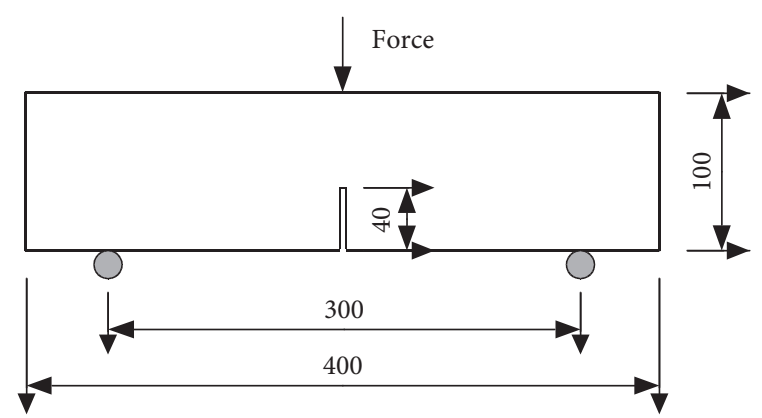

Figure 2: Loading schematic diagram (unit: $\mathrm{mm}$ ).

prefabricated cracks will physically rotate around a particular point of rotation, resulting in the vertical displacement's continuous opening and the crack opening. Based on this point, in calculating the fracture energy of TPB specimen, this paper refers to the research of Zhang and $\mathrm{Xu}$ [27] and assumes that the issue of rotation is the point of the equivalent virtual crack. The Load-CMOD curve calculates the fracture energy of the specimen. The derivation of the formula is as follows:

In the final stage of the TPB test, the pressure distribution's neutral axis gradually moves to the top of the specimen as the area of the compression zone decreases. In this case, the TPB specimen rotates along the equivalent virtual crack's tip, as shown in Figure 5. The depth of the precast gap is a, and assuming that the equal crack extends, 


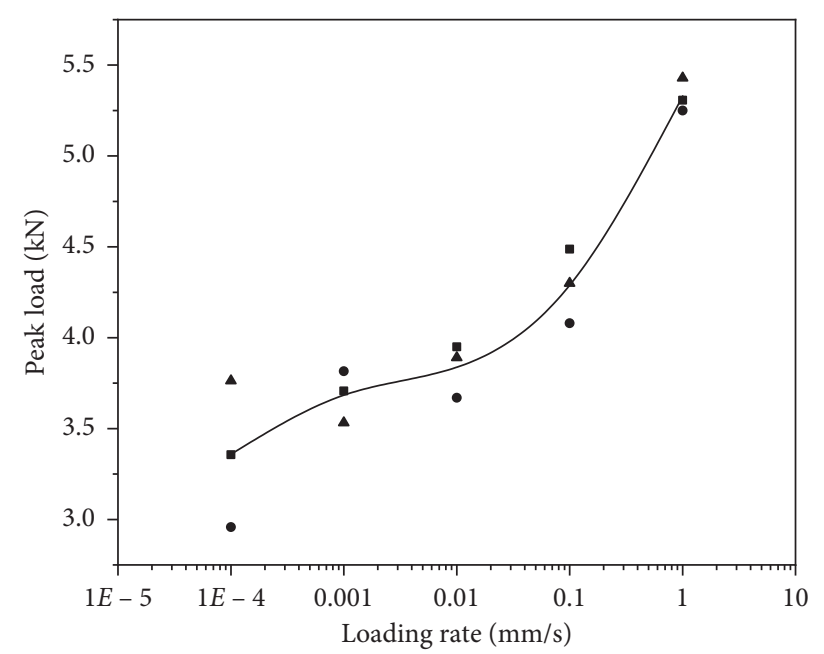

Figure 3: Influence of different loading rates on peak load.

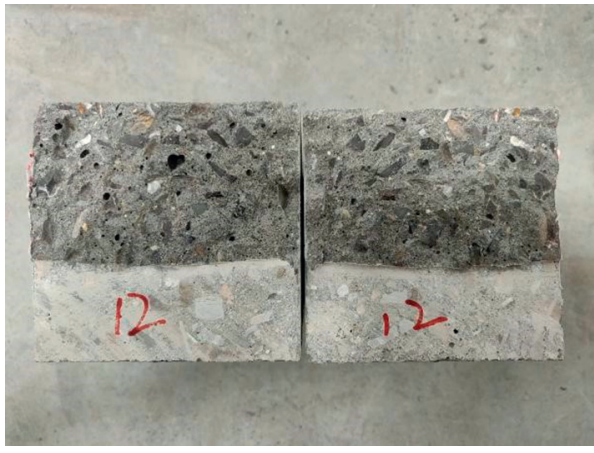

(a)

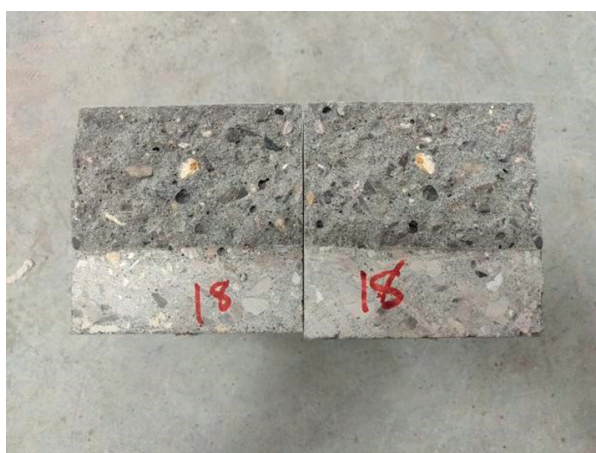

(c)

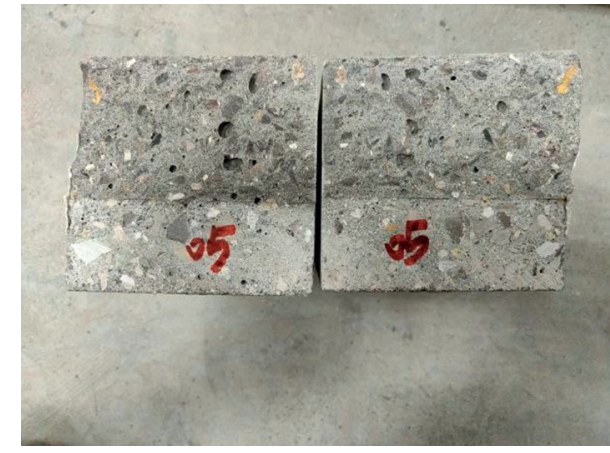

(b)

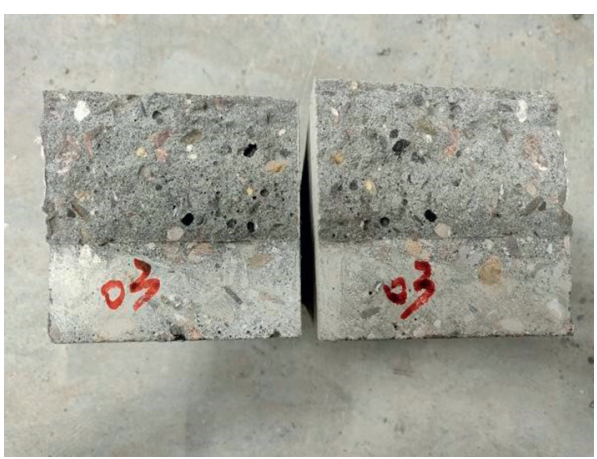

(d)

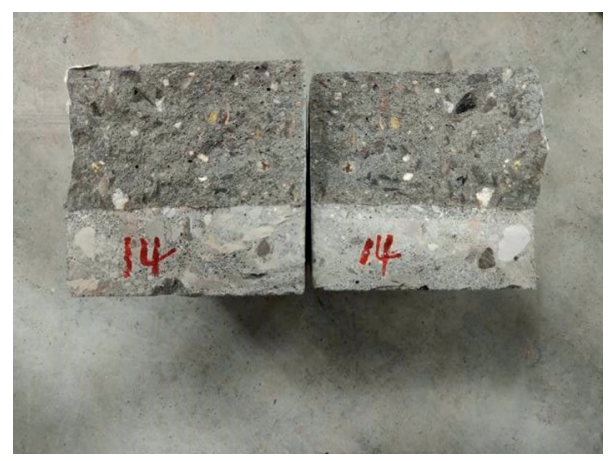

(e)

FIgURE 4: The fracture surfaces of concrete specimens. (a) $1 \mathrm{~mm} / \mathrm{s}$. (b) $0.1 \mathrm{~mm} / \mathrm{s}$. (c) $0.01 \mathrm{~mm} / \mathrm{s}$. (d) $0.001 \mathrm{~mm} / \mathrm{s}$. (e) $0.0001 \mathrm{~mm} / \mathrm{s}$. 


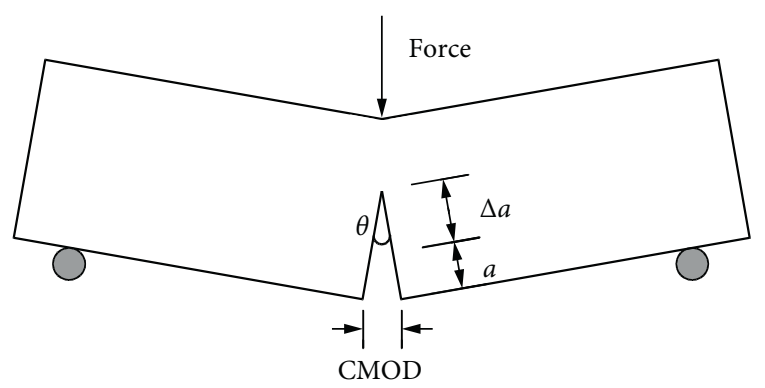

Figure 5: Dynamic fracture model of the specimen under TPB fracture test.

the rotation angle of the beam can be approximately expressed as follows:

$$
\theta=\frac{\mathrm{CMOD}}{\Delta a+a}
$$

For further simplification, we set: $\alpha=\Delta a /(a+\Delta a)$, $\beta=\mathrm{CMOD} / \mathrm{CMOD}_{c}$, the $C M O D_{c}$ in equation (1) is the critical opening displacement (the crack opening displacement corresponding to the maximum load) and sets:

$$
\alpha=\sum_{i=0}^{n} A_{i} \beta^{i}
$$

In equation (2), $A_{i}$ is coefficient, the value of $n$ is usually 4 or 5. Equation (3) can be used to calculate the $\Delta a$ according to the Load-CMOD [24].

$$
\Delta a=\frac{2}{\pi}(D) \arctan \sqrt{\frac{\text { CMODEt }}{32.6 P}-0.1135}-a .
$$

In equation (3), $D$ is the height of the specimen and $t$ is the thickness of the specimen, $E$ is the elastic modulus of the specimen.

Substituting equations (2) into equation (1), we can get the following:

$$
\theta=(1-\alpha) \frac{\mathrm{CMOD}}{a}=\frac{1}{a} \sum_{i=0}^{n} B_{i} \frac{\mathrm{CMOD}^{i+1}}{\mathrm{CMOD}_{c}^{i}} .
$$

The $B_{i}$ in equation (4) can be obtained by $A_{i}$. We assume that the work done by the external force is entirely used for the propagation of the fracture and neglects the energy dissipation outside the fracture area. When the angle of rotation of the beam reaches $\theta_{0}$ (the beam is completely destroyed), the following can be obtained:

$$
W=\int_{0}^{\theta_{0}}(M \mathrm{~d} \theta)=\int_{0}^{\theta_{0}}\left(M_{1}+M_{2}\right) \mathrm{d} \theta .
$$

In equation (5), $M_{1}$ is the bending moment caused by the load in the span, $M_{1}=P L / 4, M_{2}$ is the bending moment caused by the weight of the specimen, $M_{2}=m g L / 8$, where $L$ is span.

The derivative of equation (4) is derived into equation (5), obtaining

$$
\begin{aligned}
W & =\int_{0}^{\mathrm{CMOD}_{0}} M \cdot \frac{1}{a}\left[\sum_{i=1}^{n} C_{i} \beta^{i}\right] \mathrm{dCMOD} \\
& =\int_{0}^{\mathrm{CMOD}_{0}}\left(M_{1}+M_{2}\right) \cdot \frac{1}{a}\left[\sum_{i=1}^{n} C_{i} \beta^{i}\right] \mathrm{dCMOD} .
\end{aligned}
$$

The coefficient $C_{i}$ can be calculated by $B_{i}$. CMOD 0 is the crack opening displacement when the beam is completely destroyed.

When the P-CMOD curve is used to calculate the fracture energy, the total work $W$ can be divided into four parts $\left(W_{1}, W_{2}, W_{3}, W_{4}\right)$ if the influence of gravity and the tail curve is taken into account, as shown in Figure 6. Since $W_{3}$ is small, it is ignored. The part of the tail curve is not considered in the analysis of fracture energy. Therefore, the calculation formula of total work can be simplified as follows:

$$
W=W_{1}+W_{2}=\int_{0}^{\mathrm{CMOD}_{0}}\left(M_{1}+M_{2}\right) \cdot \frac{1}{a}\left[\sum_{i=1}^{n} C_{i} \beta^{i}\right] \mathrm{dCMOD} .
$$

Therefore, the calculation formula of fracture energy can be obtained by using equations (6) and (7), which can be expressed as follows:

$$
G_{P}=\frac{W}{A}=\frac{W}{t(D-a)} .
$$

Therefore, based on the P-CMOD curve obtained from the experiment, we can get the value of fracture energy by the formula above. In this paper, the fracture energy under five loading rates was calculated using this formula, and the results are shown in Figure 7. When the loading rate was $0.0001 \mathrm{~mm} / \mathrm{s}$, the fracture energy of the specimen was $0.097 \mathrm{~N} / \mathrm{mm}$. When the loading rate increased to $1 \mathrm{~mm} / \mathrm{s}$, the sample's fracture energy also increased to $0.144 \mathrm{~N} / \mathrm{mm}$. It can be seen that the fracture energy of concrete is greatly affected by the change of loading rate. It can be intuitively found from Figure 7 that the fracture energy increases with the loading rate increase. Since there was a large discretization in the concrete specimens' data under the working condition of $1 \mathrm{~mm} / \mathrm{s}$, it was decided to ignore it. The ultimate trend of fracture energy presented the same law as that of the peak load.

\subsection{Finite Element Simulation}

3.3.1. Bilinear Softening Function. The fracture characteristics of concrete materials are inextricably related to the state of cracks, so crack initiation and expansion have always been a subject of concern to scholars in the study of concrete fracture. In 1976, Hillerborg et al. [28] proposed a virtual crack model, which regarded the fracture process zone (FPZ) at the crack end of concrete as a virtual crack with transferable stress. After that, the characteristic softening curve of concrete becomes an integral part of the fracture model. 


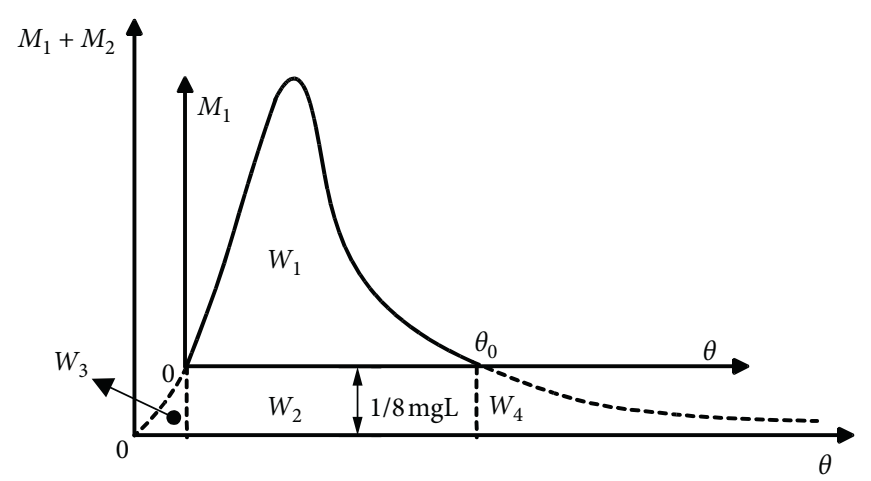

Figure 6: Dynamic fracture model of the beam under TPB test.

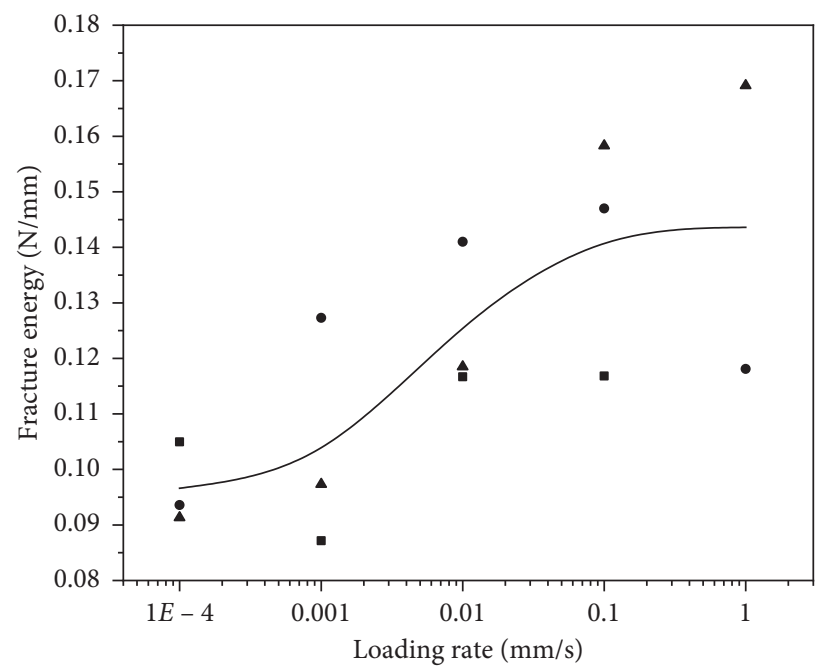

Figure 7: Effect of different loading rates on fracture energy.

Since the softening constitutive relation of concrete can describe the characteristics of FPZ, researchers have conducted extensive research in this field. In fact, for concrete (quasibrittle material), the material outside the FPZ shows linear elasticity. So the softening curve is the fundamental property of concrete material, which can be measured by direct tensile test. According to the direct tensile test, many scholars put forward different forms of softening constitutive concrete relations, including linear and nonlinear. In terms of easing the constitutive relation, the nonlinearity is more complicated. Petersson [29] first proposed the double-line softening constitutive relation and believed that the doubleline was closer to the real situation of softening constitutive relation. $\mathrm{Xu}$ and Reinhardt [30] and CEB-FIP Model Code 1990 et al. [31] proposed the corresponding modified doubleline chilling constitutive based on previous studies.

As a mixed material, concrete has many problem behaviors such as softening, strengthening, damage, and cracking. Therefore, it is not easy to establish an accurate constitutive model. However, ABAQUS, an extensive general finite element program, has a good pre- and postprocessing program and a powerful nonlinear solver. Therefore, the softening constitutive relation curve can be applied to Abaqus to simulate the fracture behavior of concrete materials accurately.

In this paper, bilinear softening constitutive relation is used to characterize the softening and cracking behavior of SCRC. Figure 8 is a classical double-line softening constitutive function. Its expression is as follows:

$$
\begin{aligned}
& \sigma=\frac{f_{t}-\left(f_{t}-\sigma_{s}\right)}{w_{s}} \quad 0 \leq w \leq w_{s}, \\
& \sigma=\frac{\sigma_{s}\left(w_{0}-w\right)}{\left(w_{0}-w\right)}, \quad w_{s} \leq w \leq w_{0}, \\
& \sigma=0 . \quad w \geq w_{0},
\end{aligned}
$$

where $w$ is crack opening displacement, $f_{t}$ is the tensile strength of concrete at room temperature, $w_{0}$ is the width of the crack opening at zero cohesion. As can be seen from Figure 8, when the tensile strength of concrete reaches the limit value, cracks begin to develop. When the crack width does not exceed $w_{s}$, the stress required for fracture propagation decreases linearly with the increase of crack width. Once the crack width reaches $w_{s}$, the stress decreases slowly 


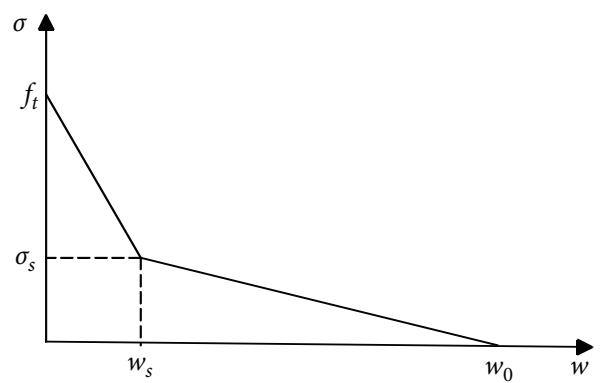

Figure 8: Bilinear softening function.

with the increase of crack width until the crack width reaches the limit value $w_{0}$.

It is found that the shape of the double-line softening constitutive curve is dependent on the size of $w_{s}, \sigma_{s}, w_{0}$. The European concrete specification [32] recommends the following formula for calculating the values of $w_{s}, \sigma_{s}$, and $w_{0}$ :

$$
\begin{aligned}
\sigma_{s} & =0.15 f_{t}, \\
w_{s} & =\frac{2 G_{f}}{f_{t}-0.15 w_{0}}, \\
w_{0} & =\frac{\alpha_{f} G_{f}}{f_{t}} .
\end{aligned}
$$

In equation (10), $G_{f}$ is the fracture energy of concrete specimens, and $\alpha_{f}$ is a parameter related to the maximum particle size $d_{\max }$ of aggregate. Based on these formulas, Zhang and $\mathrm{Xu}$ [27] introduced variable $\lambda$ when solving the alpha $\alpha_{f}$, and amend equation (10) to the following form:

$$
\begin{aligned}
\sigma_{s} & =0.15 f_{t}, \\
w_{s} & =\mu_{c}, \\
w_{0} & =\frac{\alpha_{f} G_{f}}{f_{t}}, \\
\alpha_{f} & =\frac{\lambda-d_{\max }}{8} .
\end{aligned}
$$

$\lambda$ is the parameter related to the deformation performance of concrete, which is related to the strength grade of concrete and other factors. The maximum particle size of the aggregate used in this paper is $20 \mathrm{~mm}$. In order to make the fitting between the simulated result and the measured result better, the value of $\lambda$ in this paper is 7 . According to the above formula, the bilinear softening function of SCRC can be obtained. Finally, by defining softening constitutive function, the fracture behavior of SCRC under different loading rates is evaluated by finite element simulation.

3.3.2. Comparative Analysis of Numerical Simulation and Experimental Results. To evaluate the accuracy of the prediction of SCRC beams by the bilinear softening constitutive model, the fracture behavior of concrete beams under different loading rates was simulated using the finite element method. The finite element model was established according to the size of the concrete beam used in the test, as shown in Figure 9. The maximum principal stress traction cracking criterion is adopted in the model, and the energy-based bilinear softening constitutive model is selected. To be consistent with the test's loading conditions, displacement loading is adopted in the finite element simulation. The displacement is applied to the reference point by coupling the reference point with the loading block. The C3D8R substantial element is used in concrete, and an initial notch is prefabricated in the mid-span of the beam. Shell element is used in the gap, and grid division is not needed for the crack. The discrete rigid body model is used for the loading block.

The failure forms of concrete beams with different loading rates under finite element simulation are shown in Figure 10, and Figure 11 compares the Load-CMOD curve under numerical simulation and test. Figure 11 shows that the LoadCMOD curves obtained by numerical simulation agree with the test curves at different loading rates. This indicates that the bilinear softening function mentioned in the previous section can be applied to the finite element simulation to simulate the fracture behavior of SCRC beams accurately.

To further verify that the application of the bilinear softening function determined by the above method in the finite element analysis can more accurately predict the fracture behavior of concrete beams under different loading rates, numerical simulation and experimental test data are compared and analyzed. Figure 12 shows the comparison of the peak load trend affected by loading rate under the two conditions of numerical simulation and test. In the numerical simulation, the precast concrete beams with a crack depth of $40 \mathrm{~mm}$ were subjected to the TPB tests at different loading rates of $1 \mathrm{~mm} / \mathrm{s}, 0.1 \mathrm{~mm} / \mathrm{s}, 0.001 \mathrm{~mm} / \mathrm{s}, 0.0001 \mathrm{~mm} / \mathrm{s}$, and $0.00001 \mathrm{~mm} / \mathrm{s}$, which were consistent with the test conditions. According to the numerical simulation results, with the increase of loading rate, the peak load of the concrete beam also increases, which is consistent with the test results, indicating that the bilinear softening function determined by the above method can be applied to the finite element model to predict the trend of concrete under the influence of loading rate. 


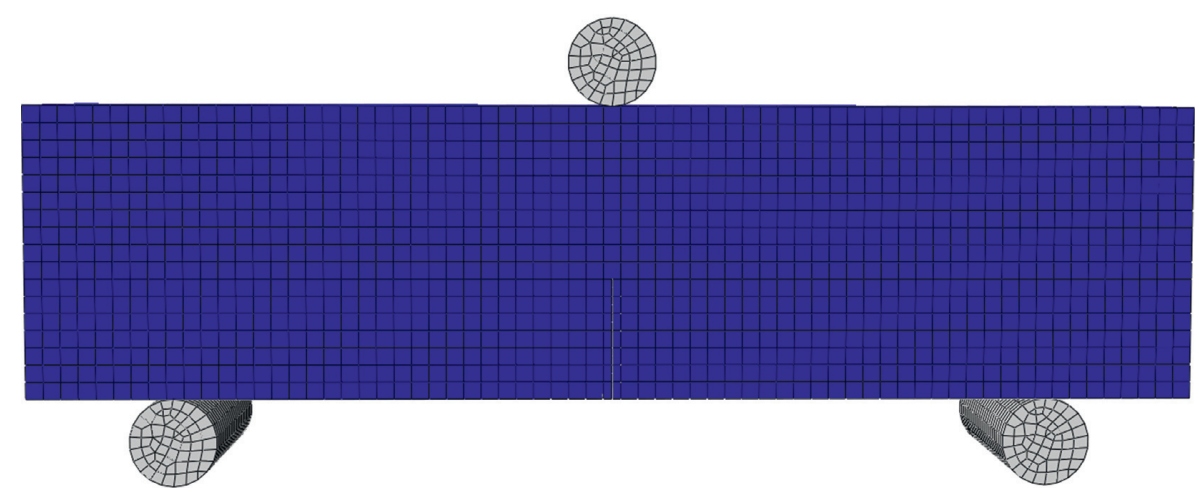

FIGURE 9: Finite element model of the concrete beams with the notch.

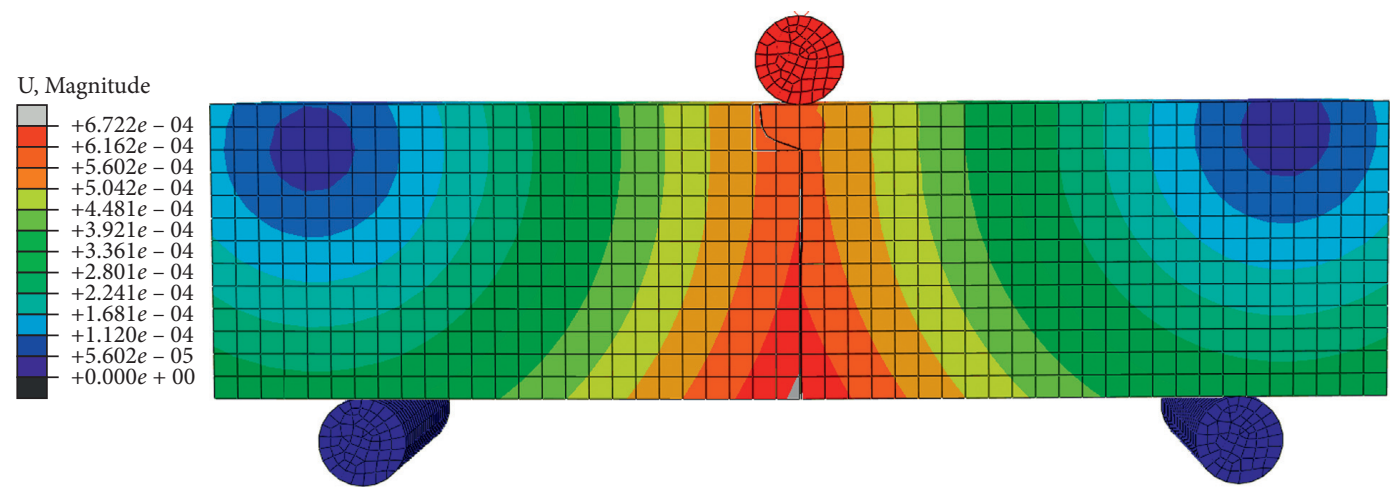

(a)

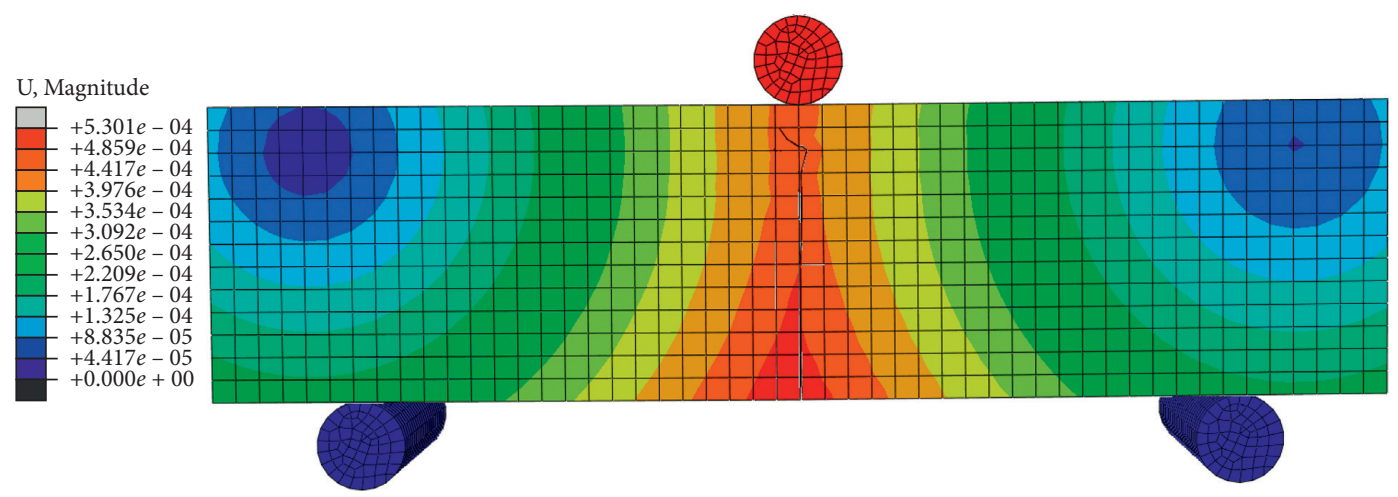

(b)

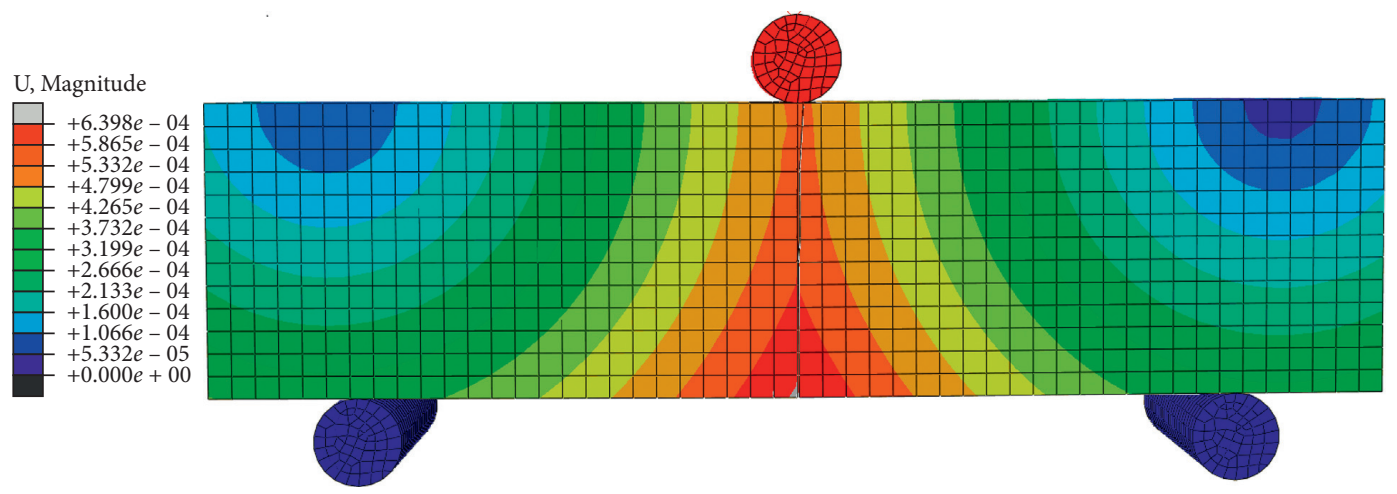

(c)

FIgURE 10: Continued. 


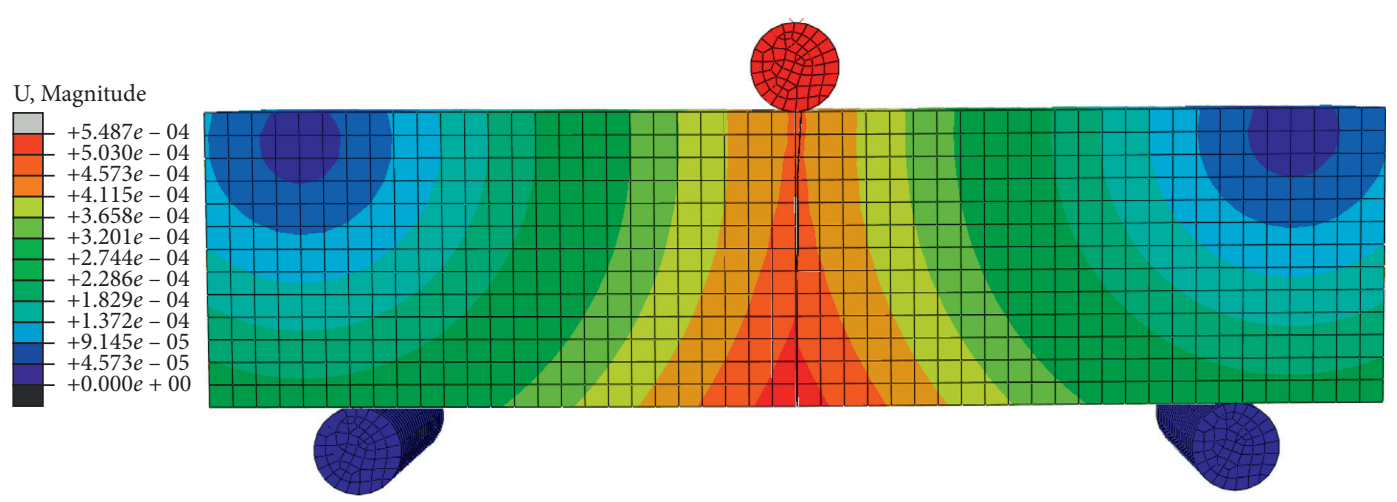

(d)

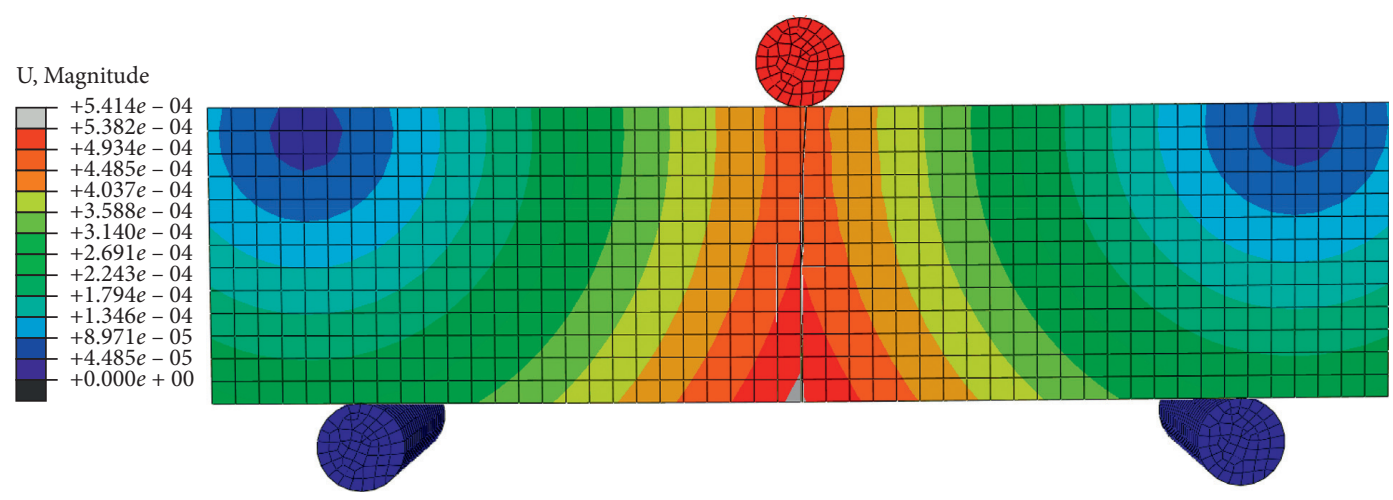

(e)

FIGURE 10: Failure forms of beams under different loading rates in finite element simulation. (a) $1 \mathrm{~mm} / \mathrm{s}$. (b) $0.1 \mathrm{~mm} / \mathrm{s}$. (c) $0.01 \mathrm{~mm} / \mathrm{s}$. (d) $0.001 \mathrm{~mm} / \mathrm{s}$. (e) $0.0001 \mathrm{~mm} / \mathrm{s}$.

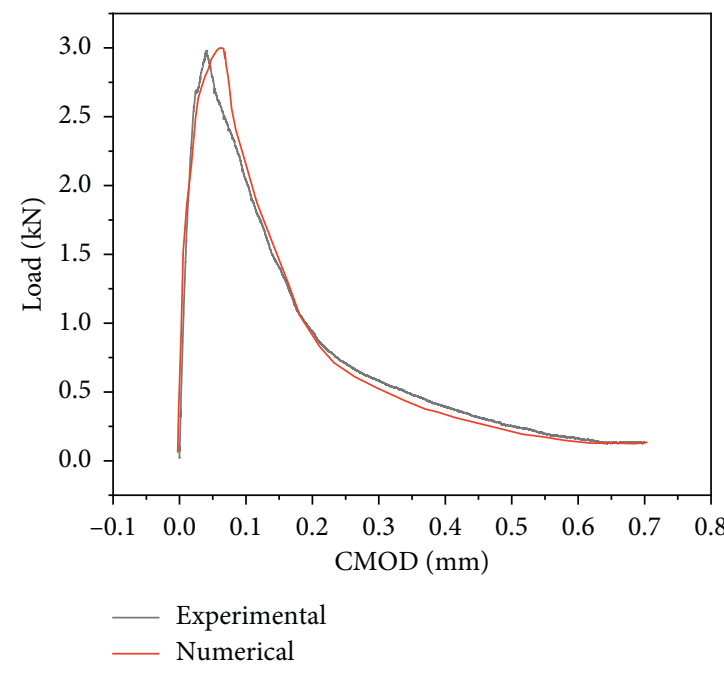

(a)

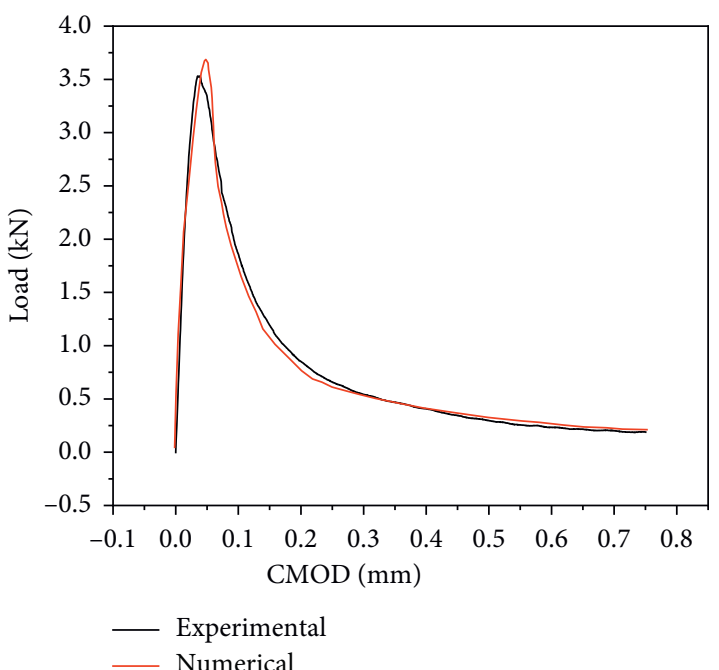

(b)

Figure 11: Continued. 


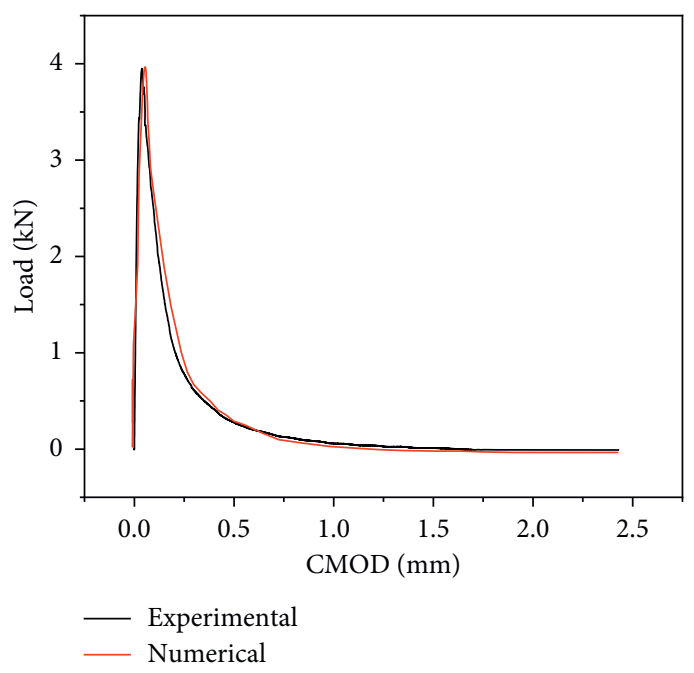

(c)

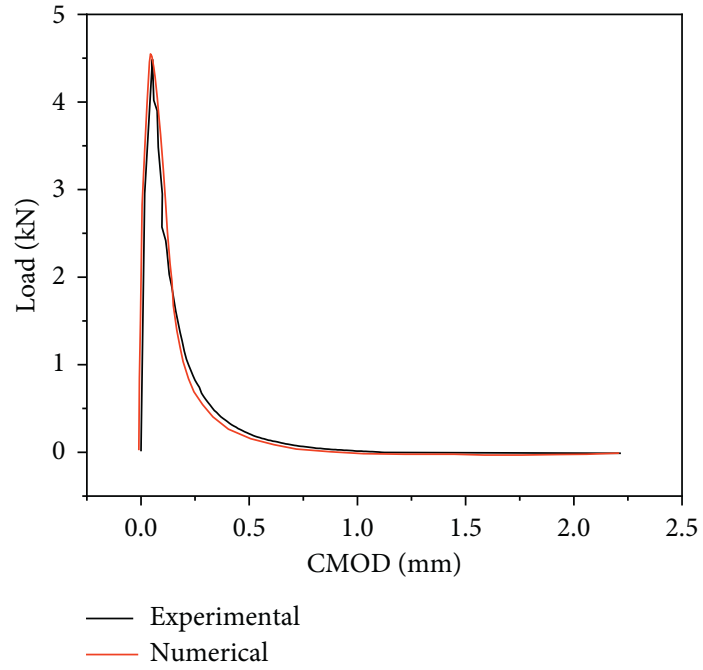

(d)

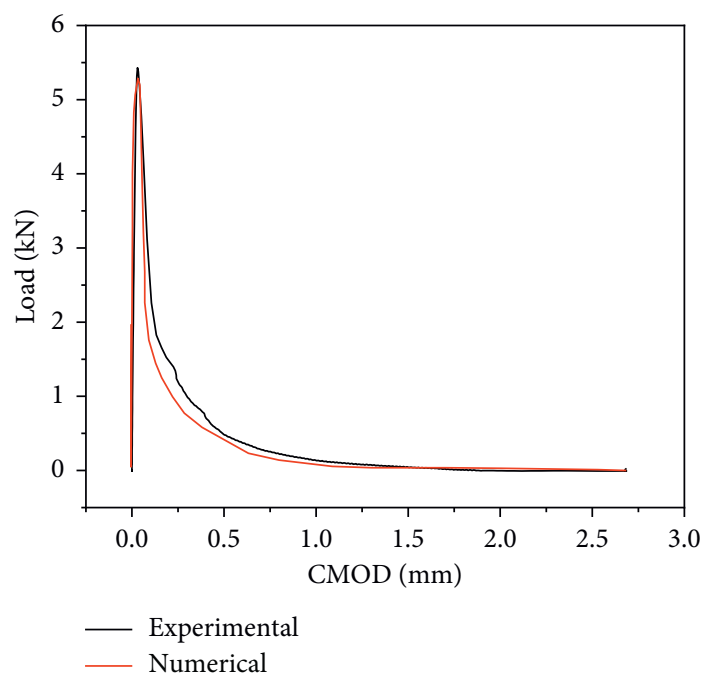

(e)

Figure 11: Comparison of the Load-CMOD curves between finite element simulation and experimental test. (a) $0.0001 \mathrm{~mm} / \mathrm{s}$. (b) $0.001 \mathrm{~mm} / \mathrm{s}$. (c) $0.01 \mathrm{~mm} / \mathrm{s}$. (d) $0.1 \mathrm{~mm} / \mathrm{s}$. (e) $1 \mathrm{~mm} / \mathrm{s}$.

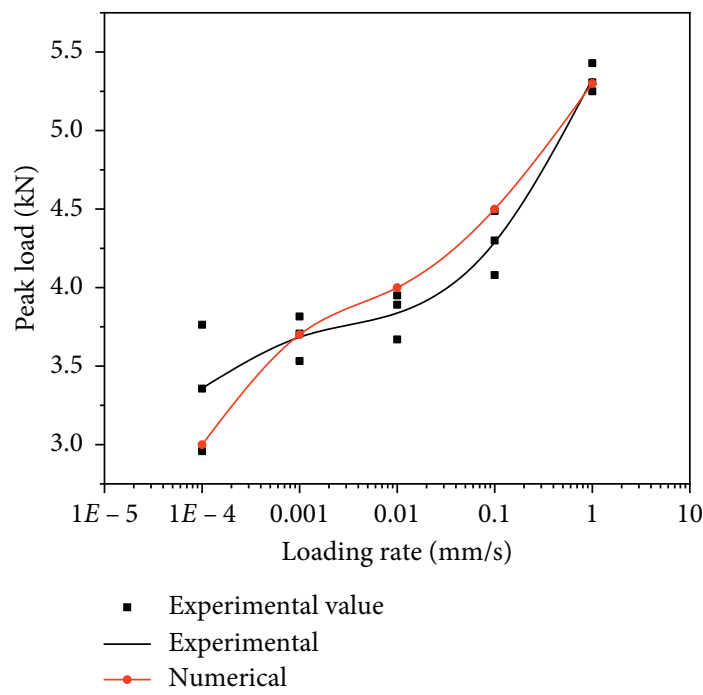

Figure 12: Comparison of the effects of loading rates on the peak load between experimental test and finite element simulation. 


\section{Conclusions}

In this paper, the fracture behavior of SCRC beams with prefabricated cracks at different loading rates under the TPB test is studied using fracture mechanics and the finite element method. The conclusions are as follows:

(1) The peak load of the SCRC beam increases with the increase of the loading rate. When the loading rate is low, the failure time of the concrete beam is long. During this period, the microcrack zone around the main crack generated by force will expand along the interface transition zone's weakest area. However, when the loading rate is high, the loading cycle is short, and the cracks tend to propagate directly through the aggregate. The aggregate's toughness is generally higher than that of the interface transition zone, which is the main reason for the increase of peak load with the loading rate growth. However, by observing the specimen's section with the naked eye, we cannot infer that the microcracks increase with the loading rate increase.

(2) Based on the P-CMOD curve obtained by the experiment, the fracture energy value was received by the formula. It is found that the fracture energy increases with the increase of the loading rate. Due to a large dispersion of data in the specimen under the condition of high speed $(1 \mathrm{~mm} / \mathrm{s})$, it was decided to ignore it, and the ultimate trend of fracture energy presented the same law as that of peak load.

(3) The bilinear softening constitutive model of SCRC was established. The bilinear softening constitutive function is embedded into the finite element model for numerical simulation. Through the analysis and comparison of the numerical simulation and test results, it is found that the trend of the concrete peak load affected by the loading rate obtained by the numerical simulation is consistent with the test results, indicating that the determined bilinear softening function can be used in the finite element model to predict the concrete affected by the loading rate.

\section{Data Availability}

All data supporting the findings of this study are present within the article.

\section{Conflicts of Interest}

The authors declare that they have no conflicts of interest.

\section{Acknowledgments}

The authors gratefully acknowledge the substantial support of National Natural Science Foundation of China (Grant no. 52009122), Zhejiang Provincial Natural Science Foundation of China (Grant nos. LQ21E090002 and LGF20E080007), Science and Technology Plan Project of Zhejiang Provincial
Department of Transportation (Grant no. 2019007), and General Research Project of Zhejiang Provincial Department of Education (Grant no. Y201941345). These supports are greatly appreciated.

\section{References}

[1] K. B. Najim and M. R. Hall, "A review of the fresh/hardened properties and applications for plain- (PRC) and self-compacting rubberised concrete (SCRC)," Construction and Building Materials, vol. 24, no. 11, pp. 2043-2051, 2010.

[2] B. Huang, G. Li, S.-S. Pang, and J. Eggers, "Investigation into waste tire rubber-filled concrete," Journal of Materials in Civil Engineering, vol. 16, no. 3, pp. 187-194, 2004.

[3] W. H. Zheng, L. J. Li, and F. Liu, "The compressive and flexural deformation of rubberized concrete," Advanced Materials Research, vol. 168, pp. 1788-1791, 2011.

[4] A. Turatsinze and M. Garros, "On the modulus of elasticity and strain capacity of self-compacting concrete incorporating rubber aggregates," Resources, Conservation and Recycling, vol. 52, no. 10, pp. 1209-1215, 2008.

[5] J. Massana, E. Reyes, J. Bernal, N. León, and E. SánchezEspinosa, "Influence of nano- and micro-silica additions on the durability of a high-performance self-compacting concrete," Construction and Building Materials, vol. 165, pp. 93-103, 2018.

[6] M. Jalal, E. Mansouri, M. Sharifipour, and A. R. Pouladkhan, "Mechanical, rheological, durability and microstructural properties of high performance self-compacting concrete containing $\mathrm{SiO} 2$ micro and nanoparticles," Materials \& Design, vol. 34, pp. 389-400, 2012.

[7] B. Persson, "A comparison between mechanical properties of self-compacting concrete and the corresponding properties of normal concrete," Cement and Concrete Research, vol. 31, no. 2, pp. 193-198, 2001.

[8] Y. W. Choi, Y. J. Kim, H. C. Shin, and H. Y. Moon, "An experimental research on the fluidity and mechanical properties of high-strength lightweight self-compacting concrete," Cement and Concrete Research, vol. 36, no. 9, pp. 1595-1602, 2006.

[9] E. Ganjian, M. Khorami, and A. A. Maghsoudi, "Scrap-tyrerubber replacement for aggregate and filler in concrete," Construction and Building Materials, vol. 23, no. 5, pp. 1828-1836, 2009.

[10] M. C. Bignozzi and F. Sandrolini, "Tyre rubber waste recycling in self-compacting concrete," Cement and Concrete Research, vol. 36, no. 4, pp. 735-739, 2006.

[11] M. Gholhaki, A. kheyroddin, M. Hajforoush, and M. Kazemi, "An investigation on the fresh and hardened properties of self-compacting concrete incorporating magnetic water with various pozzolanic materials," Construction and Building Materials, vol. 158, pp. 173-180, 2018.

[12] M. Gesoğlu and E. Güneyisi, "Permeability properties of selfcompacting rubberized concretes," Construction and Building Materials, vol. 25, no. 8, pp. 3319-3326, 2011.

[13] E. Khalil, M. Abd-Elmohsen, and A. M. Anwar, "Impact resistance of rubberized self-compacting concrete," Water Science, vol. 29, no. 1, pp. 45-53, 2015.

[14] Y. Rahmani and A. Sohrabi, "Mechanical properties of rubberized self compacting concrete containing silica fume," Advanced Materials Research, vol. 261-263, pp. 441-445, 2011.

[15] H. Rooholamini, A. Hassani, and M. R. M. Aliha, "Evaluating the effect of macro-synthetic fibre on the mechanical properties of roller-compacted concrete pavement using response 
surface methodology," Construction and Building Materials, vol. 159, no. 20, pp. 517-529, 2018.

[16] M. R. M.. Aliha, A. Razmi, and A. Mosavi, "Fracture study of concrete composites with synthetic fibers additive under modes i and iii using endb specimen," Construction and Building Materials, vol. 190, pp. 612-622, 2018.

[17] S. Shiming and S. Yupu, "Dynamic biaxial tensile-compressive strength and failure criterion of plain concrete," Construction and Building Materials, vol. 40, pp. 322-329, 2013.

[18] R. Ranade, V. C. Li, and W. F. Heard, "Tensile rate effects in high strength-high ductility concrete," Cement and Concrete Research, vol. 68, pp. 94-104, 2014.

[19] H. Rooholamini, A. Hassani, and M. R. M. Aliha, "Fracture properties of hybrid fibre-reinforced roller-compacted concrete in mode i with consideration of possible kinked crack," Construction and Building Materials, vol. 187, no. 30, pp. 248-256, 2018.

[20] A. DaneshfarM. Hassani et al., "Evaluating mechanical properties of macro-synthetic fiber-reinforced concrete with various types and contents," Strength of Materials, vol. 49, no. 5, pp. 618-626, 2017.

[21] M. Nitka and J. Tejchman, "Modelling of concrete fracture at aggregate level using FEM and DEM based on X-ray $\mu \mathrm{CT}$ images of internal structure," Engineering Fracture Mechanics, vol. 147, pp. 13-35, 2015.

[22] S. Firoozi, M. Dehestani, and N. B. Navayi, "Effect of water to cement ratio on the mode III fracture energy of self-compacting concrete," Materials and Structures, vol. 51, no. 4, p. $80,2018$.

[23] H. H. N. Chen, R. K. L. Su, S. L. Fok, and H. G. Zhang, "Fracture behavior of nuclear graphite under three-point bending tests," Engineering Fracture Mechanics, vol. 186, pp. 143-157, 2017.

[24] N. Trivedi, R. K. Singh, and J. Chattopadhyay, "Size independent fracture energy evaluation for plain cement concrete," Fatigue \& Fracture of Engineering Materials \& Structures, vol. 38, no. 7, pp. 789-798, 2015.

[25] J. S. Kalyana Rama, D. R. Chauhan, M. V. N. Sivakumar, A. Vasan, and A. R. Murthy, "Fracture properties of concrete using damaged plasticity model-A parametric study," Structural Engineering and Mechanics, vol. 64, no. 1, pp. 59-69, 2017.

[26] I. Vegt, V. K. Breugel, and J. Weerheijm, "Failure mechanisms of concrete under impact loading. Fracture mechanics of concrete and concrete structures," FraMCoS-, vol. 6, no. 1, pp. 579-587, 2007.

[27] X. Zhang and S. Xu, "Determination of fracture energy of concrete three-point bending beam by load-crack opening displacement Curve," Journal of Hydraulic Engineering, vol. 39, no. 6, pp. 714-719, 2008, in Chinese.

[28] A. Hillerborg, M. Modéer, and P.-E. Petersson, "Analysis of crack formation and crack growth in concrete by means of fracture mechanics and finite elements," Cement and Concrete Research, vol. 6, no. 6, pp. 773-781, 1976.

[29] P. E. Petersson, Crack Growth and Development of Fracture Zones in Plain Concrete and Similar materials Report No. TVBM-1006, Division of Building Materials, Lund Institute of Technology, Lund, Sweden, 1981.

[30] S. Xu and H. W. Reinhardt, "Determination of double-K criterion for crack propagation in quasi-brittle fracture, Part II: analytical evaluating and practical measuring methods for three-point bending notched beams," International Journal of Fracture, vol. 98, no. 2, pp. 151-177, 1999.
[31] Euro CEB Comite 1991 International du Beton, "CEB-FIP model Code 1990, final draft 1991,” Bulletin d'Information.vol. 203, pp. 21-216, 1990.

[32] S. Xu and H. W. Reinhardt, "A simplified method for determining double- $K$ fracture parameters for three-point bending tests," International Journal of Fracture, vol. 104, no. 2, pp. 181-209, 2000. 